\title{
El galeón de Manila San Damián (1661-1662): estructuración y organización de un galeón en el pacífico mexicano
}

José Miguel Herrera Reviriego jherrera@uji.es 
En 1662, el galeón de Manila San Damián abandonó el puerto de Acapulco y se hizo al fragor de las olas del Pacífico. No se trataba de una nao de China más: se trataba de una embarcación peculiar. El devenir de los acontecimientos la había acabado otorgando un cariz especial, casi único, que la separaba claramente de la estructura general de los galeones de Manila de su época.

\section{Objetivos}

Nos encontramos, por tanto, ante un suceso particular, sí, pero no debemos pensar en él como un caso aislado, sino como una variante del modelo general. Por ello, esperamos que el caso particular de la San Damián, aporte unos resultados que ayuden a alcanzar un mayor conocimiento sobre el funcionamiento general de los galeones de Manila, tanto a mediados del siglo XVII, como en otras épocas y perspectivas históricas.

\section{Material y método}

Por esta razón, hemos llevado a cabo un estudio pormenorizado de las particularidades de este navío, mediante el cual, nos adentraremos y profundizaremos en las características de estos viajes transpacíficos; así como en su estructura y sistematización. Siendo este tipo de estudios microhistóricos, bajo nuestro punto de vista, de gran ayuda para alcanzar mediante el detalle y el conocimiento singularizado, una mayor profundidad del proceso global.

\section{Resultados}

Debido a la larga y peligrosa travesía, a la elevada carga y a las condiciones particulares de la navegación del Pacífico, los galeones de Manila solían ser fabricados en exclusiva para atender esta empresa, construyéndose especialmente para resistir las más aciagas adversidades. Por ello, no solía ser conveniente ni habitual, que un navío no especializado para soportar estas duras condiciones, acabara desempeñando el rol de galeón de Manila, siendo muy escasos los casos en que esto llegaba a ocurrir.

La San Damián constituye uno de estos casos especiales. Construida en Guatemala, con el único objetivo de emprender viajes de corta y media distancia, contra todo pronóstico, acabó realizando el viaje regular sin escalas más largo y peligroso de su tiempo. Pero, ¿como acabó este pequeño navío guatemalteco reconvertido en un galeón de Manila?. Para 
responder esta pregunta debemos retrotraernos a 1660 y trasladarnos geográficamente hasta las lejanas islas Filipinas.

En este año, la nao Nuestra Señora de la Concepción, cargada con los más exquisitos y variados productos asiáticos de cuantos llegaban hasta este archipiélago, emprendió viaje desde el puerto de Lampón -situado en la parte sureste de Luzón- hasta Acapulco. Mas la suerte no estuvo de su parte, y el insigne galeón de Manila, tuvo que dar media vuelta sólo tres días después de abandonar las islas al verse arrancado uno de sus árboles por una fuerte tormenta.

Este contratiempo conllevó terribles consecuencias tanto para el comercio como para la economía de las islas: la reparación de un galeón era un proceso lento y complicado, por lo que era impensable conseguir que este galeón estuviera listo para cruzar el Pacífico ese mismo año.

Debido a ello, no hubo más remedio que dejar las mercancías en tierra, y con ellas las fuertes inversiones acometidas por los vecinos de Manila, y esperar que el galeón estuviese preparado para el siguiente año. Las pérdidas derivadas de este percance resultaron notables, sobre todo para una ciudad tan dependiente de la feria de Acapulco como era Manila, y para sus vecinos, necesitados de la inyección anual de capital del galeón.

Por su parte, la Gobernación también acusó sensiblemente el percance de la Nuestra Señora de la Concepción. No eran buenos tiempos para las islas, ya que a la inseguridad propia de toda zona fronteriza, se le unían unos preocupantes problemas económicos, agravados ante la falta del situado de ese año y los gastos derivados de la reparación de la nao.

Por otra parte, la perspectiva mexicana de este contratiempo no era mucho mejor. A los problemas económicos y comerciales, derivados de la ausencia del galeón de Manila del puerto de Acapulco, se le debía sumar la inseguridad subsiguiente a la falta del vínculo comunicativo entre el Virreinato novohispano y la Gobernación asiática.

Desde la separación de las coronas de Castilla y Portugal, la comunicación oficial entre Filipinas y Madrid -salvo en contadas y espaciales circunstancias- se realizaba únicamente por la vía americana. Por lo que la ausencia del galeón de aguas mexicanas, producía una total carencia de información sobre la situación de la Gobernación asiática, por lo menos durante un año. Esta privación de noticias sobre las islas, resultaba verdaderamente preocupante en la coyuntura de la época, pues como ya hemos visto, el archipiélago no contaba con una buena situación económica que junto a sus dificultades defensivas, hacía que se temiera por la supervivencia de la población de Manila y por el mantenimiento de las armas hispánicas en ella.

Ante esta perspectiva, desde el virreinato, se comenzó a barajar la posibilidad de enviar ese mismo año un galeón desde Acalpulco sin esperar que llegara nao alguna desde Filipinas. Decantándose finalmente por esta posibilidad, al acatar la nueva normativa reguladora del tránsito de los galeones de Manila, generada por la recién expedida Real Cédula 
de 14 de febrero de $1660 .^{1}$ En ella, se obligaba a los virreyes de Nueva España a tener preparados galeones en Acapulco, para que en el caso de que algún año la nao enviada desde Filipinas no pudiera alcanzar su destino, las islas no se vieran privadas de su socorro anual.

De este modo, bajo la presión de la incertidumbre y la legalidad, el virrey conde de Baños -quien ocupaba el cargo desde 1660 en sustitución del duque de Albuquerque- emprendió la organización de un nuevo viaje transpacífico. Este, tendría la peculiaridad de ser organizado únicamente por novohispanos americanos, sin la interferencia e intermediación de cargos nombrados al otro lado del Pacífico, quienes solían actuar en gran medida siguiendo las órdenes dadas por los gobernadores filipinos.

Esta peculiaridad, conformará un carácter especial al galeón, ya que en él, no tuvo lugar la tradicional cooperación entre mexicanos y filipinos que caracterizaba la organización de las naos transpacíficas salidas desde Acapulco. Por lo que, la San Damián, permanecerá al margen de los tradicionales enfrentamientos y discrepancias que solían mantener mexicanos y filipinos, tanto de manera individual como colectiva, para hacer valor sus intereses personales sobre los de sus convecinos. Por ello, nos encontramos ante la organización de un galeón en la que prevalecerán las opiniones e intereses mexicanos, sin signos de cooperación con Filipinas y envuelto en una cierta paz social.

Pero en cambio, la estructuración de la San Damián no se vio privada de polémica, ya que desde un primer momento, la organización del navío tuvo que sobrevivir a numerosas dificultades.

La primera de ellas, fue la ausencia en Acapulco de navío alguno que pudiera cumplir con los requisitos mínimos necesarios para acometer un viaje hasta Manila, ya fuese en cuanto a la resistencia de los materiales utilizados, como en la capacidad de carga. Para solucionar este problema, el virrey conde de Baños decidió realizar una junta general de hacienda, en la que se plantearon las distintas alternativas y opciones existentes para solucionar este escollo. Ante la imposibilidad de la construcción de un navío de las características y proporciones de un galeón con los recursos y mano de obra disponibles en Acapulco, la junta decidió buscar un navío en la vecina Guatemala que cumpliera con los requisitos mínimos para garantizar la seguridad del viaje. Para ello, se envió una carta al presidente de la Audiencia de Guatemala, Martín Carlos de Meneoz, para que buscara entre los puertos de su jurisdicción una nave de 300 toneladas que estuviera disponible para su compra, remitiéndola lo antes posible a Acapulco.

Por su parte, Meneoz respondió al virrey, en carta de 17 de febrero de 1661, explicando que había encontrado una nave que cumplía con los requisitos exigidos en el puerto de Realejo, pero que desgraciadamente, no contaba con los medios ni con los hombres para enviarla hasta

${ }^{1}$ Archivo General de Indias (en adelante AGI), Filipinas 23, R.2, N.4. 
Acapulco. Ante la falta de una alternativa mejor, y a tenidas cuentas que seguían sin llegar noticias desde Manila, el 14 de septiembre de 1661, se decidió enviar a Realejo a dos pilotos acompañados por 20 marineros, a quienes se encomendó la misión de llevar la nave hasta el puerto de salida del galeón lo antes posible.

Mientras tanto, en Acapulco, la maquinaría encargada de organizar el resto de preparativos para el envío del galeón hasta Filipinas se puso en marcha. Debido a la baja tasa de población y a la escasa presencia de productos manufacturados y agrícolas que tenía lugar en el hinterland de Acapulco, la mayoría de los artículos que hacían posible la buena marcha del galeón, debían ser trasportados desde otros enclaves novohispanos. De este modo, largas caravanas de mulas jalonaron el camino hasta Acapulco, transportando en ellas bizcocho y carne de Puebla de los Ángeles, textiles de México o productos relacionados con la marinería provenientes de Veracruz. Mientras tanto, una multitud de soldados tanto voluntarios, como forzados-, marineros y eclesiásticos de diferentes órdenes religiosas, se iban concentrando en los alrededores de Acapulco, mientras esperaban la llegada de la San Damián desde Guatemala. Los preparativos del viaje transpacífico iban a buen ritmo, y parecía que todo estaría listo cuando la San Damián llegara al fin a puerto.

El 1 de marzo de 1662, la nao San Damián llegó a Acapulco ante la sorpresa de los allí presentes, que no esperaban un buque de semejante fisonomía. La embarcación, no presentaba las características estructurales deseables para un galeón; era un navío bastante frágil y con pocas posibilidades reales de cruzar el Pacífico. ${ }^{2}$ Además, a pesar de que el virrey conde de Baños había solicitado de forma explicita una embarcación de 300 toneladas a la Audiencia de Guatemala, la capacidad de carga de la San Damián solo alcanzaba las 230. Esto suponía un grave inconveniente, pues los preparativos que se habían llevado a cabo en Acapulco para la carga y composición de la nave, eran los necesarios para una embarcación de un tonelaje mucho mayor. Por lo que, si la San Damián se acababa haciendo a la mar, un elevado número de mercancías, alimentos para el consumo durante el viaje y tripulantes, deberían quedarse en Acapulco y aguardar al siguiente galeón, con los gastos adicionales que esto suponía para la exhausta caja mexicana.

En cualquier caso, la decisión de convertir a la San Damián en galeón de Manila, no se podía revocar. Ya no era posible dar marcha atrás y buscar otro navío: la San Damián era la única opción. En 1662 tampoco había llegado galeón alguno de Filipinas, y se temía el peor desenlace posible para la presencia hispánica en las islas, por lo que era necesario que la San Damián partiera inmediatamente, sin importar las condiciones

${ }^{2}$ Carta de Diego Salcedo de 24 de marzo de 1663, AGI, Filipinas 81, N.65: «siendo navichuelo de tan poco porte que se tiene pocas esperanças pudiesse llegar allá». 
en que lo hiciera. Además, el tiempo pasaba rápidamente, y si se retrasaba mucho más la expedición, se incurría con la posibilidad de encontrarse con los vientos monzónicos ante las costas filipinas, con el consiguiente riesgo para carga y tripulación.

Consecuentemente, toda la estructuración prevista y llevada a cabo para la San Damián, debía ser revisada y alterada para hacer frente a las nuevas condiciones del galeón. Por ello, se decidió cambiar rápidamente la estructuración de la nave, y priorizar las necesidades de la carga: el situado en plata se remitiría por entero según lo previsto, pero la cantidad de géneros y vituallas para el camino se vieron reducidas considerablemente. Del mismo modo, se priorizó el embarque de marineros y soldados voluntarios, eligiéndose entre ellos los que presentaban unas mejores condiciones físicas, mientras que todos los forzados quedaron en Acapulco. Esta restricción también afectó a los religiosos que tenían previsto embarcarse hacía Filipinas, pues únicamente se concedió licencia para ello a 15 jesuitas y a un agustino descalzo. Reduciéndose la tripulación únicamente a 150 hombres, con los que la San Damián esperaba ser capaz de cruzar el Pacífico, aunque desde Acapulco tuvieran pocas esperanzas en ello.

En cuanto a los gastos efectuados en la San Damián, a pesar del reducido tamaño final del galeón, la cantidad de dinero invertida en él, fue bastante considerable. Según las cuentas facilitadas por el virrey conde de Baños, el gasto total de la San Damián ascendió a 436.604 pesos, 5 tomines y 4 granos, desglosadas de la siguiente manera:

Tabla 1. Coste de la San Damián

\begin{tabular}{|l|l|}
\hline \multicolumn{1}{|c|}{ Concepto } & \multicolumn{1}{c|}{ Importe } \\
\hline Situado & 156.000 pesos \\
\hline $\begin{array}{l}\text { Compra de géneros que se remitieron a dichas islas y } \\
\text { los gastos que se hicieron de remitirlos de Veracruz a } \\
\text { Acapulco }\end{array}$ & $\begin{array}{l}55.092 \text { pesos } 2 \text { tomines } \\
8 \text { granos }\end{array}$ \\
\hline $\begin{array}{l}\text { Dinero remitido por los jueces oficiales de Acapulco } \\
\text { para el despacho de la nao }\end{array}$ & 28.000 pesos \\
\hline $\begin{array}{l}\text { Pago a cargos militares: capitanes, sargento mayor, } \\
\text { alféreces y sargentos destinados a Filipinas }\end{array}$ & 65.259 pesos 2 tomines \\
\hline $\begin{array}{l}\text { Pago a la infantería, artilleros, marineros y grumetes } \\
\text { destinados a Filipinas }\end{array}$ & 14.916 pesos 7 tomines \\
\hline $\begin{array}{l}\text { Para sustento de los religiosos que van e irán a las } \\
\text { Filipinas }\end{array}$ & $\begin{array}{l}34.518 \text { pesos } 2 \text { tomines } \\
4 \text { granos }\end{array}$ \\
\hline $\begin{array}{l}\text { Infantería al puerto de Quemavaca para el socorro de } \\
\text { las Filipinas en 1661 }\end{array}$ & 555 pesos \\
\hline Compra de 6 pipas, 1 veta de jarcia y otros géneros & 3.669 pesos 6 tomines \\
\hline
\end{tabular}




\begin{tabular}{|l|l|} 
con su flete al puerto de Acapulco en Veracruz & 6 granos \\
\hline Compra de lona y su flete de Veracruz a Acapulco & 574 pesos 4 tomines \\
\hline $\begin{array}{l}\text { Artilleros, forzados, envío de mulas y envío del piloto } \\
\text { mayor desde Veracruz }\end{array}$ & 2.303 pesos \\
\hline $\begin{array}{l}100 \text { pujas compradas en Veracruz para el puerto de } \\
\text { Acapulco para hacer aguada }\end{array}$ & 2.778 pesos 4 tomines \\
\hline Total: & 9.888 pesos \\
\hline Coste de la compra de la nao San Damián & 42.926 pesos \\
\hline Total & $\begin{array}{l}436.604 \\
\text { tomines } \\
4 \text { granos pesos } 5\end{array}$ \\
\hline
\end{tabular}

El coste de la organización de este viaje era ciertamente elevado, sobre todo, si tenemos en cuenta que la San Damián presenta cifras relativamente cercanas a la de otros galeones enviados durante el mandato del virrey duque de Albuquerque y que presentaban unos tonelajes mucho mayores:

Tabla 2. Costes y situado de los galeones de Manila (1653-1663)

\begin{tabular}{|l|l|l|l|}
\hline Año salida & Embarcación & Costes totales $^{\mathbf{3}}$ & Situado $^{\mathbf{4}}$ \\
\hline 1653 & San Francisco Xabier & 561.249 pesos & $\begin{array}{l}227.000 \\
\text { pesos }\end{array}$ \\
\hline 1654 & San Diego & 500.000 pesos & $\begin{array}{l}153.000 \\
\text { pesos }\end{array}$ \\
\hline 1655 & San Francisco Xabier & 500.000 pesos & $\begin{array}{l}225.000 \\
\text { pesos }\end{array}$ \\
\hline 1658 & - & 585.000 pesos & $\begin{array}{l}196.000 \\
\text { pesos }\end{array}$ \\
\hline 1662 & San Damián & 436.504 pesos & $\begin{array}{l}156.000 \\
\text { pesos } \\
\end{array}$ \\
\hline 1663 & San José & 606.550 pesos & $\begin{array}{l}220.000 \\
\text { pesos }\end{array}$ \\
\hline
\end{tabular}

El alto coste de la San Damián, no resulta tan sorprendente sí tenemos en cuenta los lucrativos negocios que se podían obtener con una organización poco ortodoxa de los galeones de Manila. Además, hay que tener en cuenta, las continuas denuncias vertidas contra los altos cargos novohispanos, en las que se acusaba a ellos y a sus familias de enriquecerse a costa del comercio transpacífico y de realizar diversos desfalcos y corruptelas en la compra de mercancías para Acapulco (Arenas

${ }^{3}$ Los costes totales del galeón proceden de cuentas facilitadas por los virreyes de Nueva España, Duque de Albuquerque y Conde de Baños.

${ }^{4}$ Las cantidades del situado son aportadas por el gobernador de Filipinas Sabiano Manrique de Lara (1653-1663). 
Frutos, 2010: 563-571). Por todo ello, puede que los gastos aquí representados y extraídos de las cuentas facilitadas por el virrey, fueran incrementados deliberadamente para ocultar toda una serie de fraudes en la organización del viaje.

Los intereses y corruptelas de los altos cargos virreinales, se dejaron entrever en otros ámbitos como en la elección de los mandos de a bordo de la San Damián. En este caso, los nombramientos recayeron sobre criados y gente de confianza del conde de Baños, que aunque no presentaban unos elevados conocimientos náuticos, ni experiencia en la navegación del Pacífico, si gozaban de la parcialidad del virrey. ${ }^{5}$

Esta elección, se situaba en contra de la tónica habitual de la selección de capitanes generales y cavos para los galeones, ya que este puesto recaían normalmente en cargos filipinos vinculados al ejército que gozaran de cierto prestigio en las islas.

Además, esta elección alteraba los estándares en la relación entre cargos mexicanos y capitanes generales de los galeones. Ya que los capitanes filipinos, solían cumplir órdenes precisas entregadas por los gobernadores antes de su partida, sobre la relación que debían mantener con los cargos mexicanos y sobre su estancia en Acapulco. A las que habría que sumar, una serie de ordenanzas e instrucciones sobre su proceder en alta mar que siguiendo los criterios del gobernador, reglamentaban el devenir y vida a bordo del galeón durante la travesía. Por lo que los capitanes generales de los galeones, únicamente solían acometer órdenes expedidas por los virreyes si estas tenían lugar en territorio mexicano, siguiendo las instrucciones del gobernador una vez se hacían a alta mar.

En este caso, y al no contar la San Damián con intervención filipina, las instrucciones relativas al galeón fueron expedidas directamente desde México, mostrándonos rasgos y características importantes para entender la vida a bordo de este galeón y la visión que se tenía de él desde Nueva España.

Estas instrucciones se pueden dividir en varios apartados según sus características: las que regulaban la actividad del galeón y de su capitán general en Acapulco, las que ordenaban la vida a bordo en la San Damián, y las que reglamentaban tanto la seguridad como la ruta de la nave.

Entre las disposiciones sobre la actividad en Acapulco, cave destacar, las ordenanzas sobre la buena correspondencia que debía mantener el capitán general de la San Damián con los oficiales reales de aquel puerto y con el castellano del fuerte de San Diego. Esta instrucción, pretendía evitar que la salida del galeón -que el virrey había fijado para el 25 de marzo-, se retrasara debido a problemas jurisdiccionales y personales con las autoridades de Acapulco o que se crearan conflictos innecesarios en

${ }^{5}$ Memorial de Francisco García del Fresno, 24 de marzo de 1663, AGI Filipinas, 9, R.3, N.41: «Fue fuerza al dicho señor virrey embiar por cavo del dicho navio a un criado suyo.». 
este puerto. ${ }^{6}$ También se le pedía al capitán general, que vigilara que no se alteraran las mercancías cargadas -que se modificara la disposición de los fardos o que se introdujeran géneros fuera de registro- una vez atracado el galeón en Acapulco, ni que dejara subir ni bajar de a bordo, a ninguna persona sin licencia, evitando en la medida de lo posible que se efectuaran registros por las autoridades portuarias. ${ }^{7}$ Este temor a los registros y a la intromisión de los oficiales reales en el cargamento de la nave, deja entrever, una vez más, los negocios fraudulentos que mantenían el virrey y otros altos cargos en las bodegas de la San Damián.

Por su parte, las disposiciones reguladoras de la vida a bordo, comprendían un variado número de aspectos, desde la alimentación de la tripulación, hasta el cumplimiento de las obligaciones religiosas. Así, entre ellas, se impedía vender frutas de Acapulco a bordo -ya que estas solían producir enfermedades entre la tripulación ${ }^{8}$ - se regulaban las raciones de comida para los viajeros o se prohibía dar vino, destinado a los reales almacenes, a los oficiales. ${ }^{9}$ También, se obligaba a que los días en que la mar estaba en calma y la navegación no exigía excesivo trabajo, se celebrara misa a bordo acudiendo el general a ella y rezando en común el rosario. $^{10}$

Por otro lado, destaca el elevado número de instrucciones relativas a la seguridad y defensa de la nao. Esta situación no resulta sorprendente, ya que desde que el galeón Santa Rosa fue apresado en 1588 por piratas ingleses, habían sido numerosos los ataques sufridos durante los viajes a Filipinas. ${ }^{11}$ Por ello, se establecieron turnos de guardia, se procuró que las armas estuvieran limpias y dispuestas para la defensa, se prohibió gastar pólvora sin motivo ni justificación y, en último término, se instó a los tripulantes a que en caso de enfrentamiento se luchara hasta la muerte. ${ }^{12}$ También se ordenó al capitán general a que hiciese lo posible para que la

\footnotetext{
${ }^{6}$ Instrucciones otorgadas al capitán general de la San Damián, AGI, Filipinas 23, R.2, N.4: «Tendrá toda buena correspondencia con el castellano de Acapulco, visitador y oficiales reales de aquel puerto, escusando qualesquiera géneros de competencias para que por todos como ministros de su magestad se procure ganar tiempo en la embarcación."

${ }^{7}$ Instrucciones otorgadas al capitán general de la San Damián, AGI, Filipinas 23, R.2, N.4: «Que rreciva la gente de mar y guerra con todo cuidado, y no deje desembarcar ninguno porque la ha de entregar caval y por el rregistro y no consiente lo pongan más en la lista por defraudar raciones. $Y$ si le quisieren atropellar visita y registro, haga protestas y buelba a pasar muestra por ante el secretario de la nao, y atento a que no lleva forçados no se pone la forma que con ellos se devía observar.»

${ }^{8}$ Ibidem: «Hordenará que en la tienda del contramaestre no se venda fruta de Acapulco por las enfermedades que hordinariamente causa.»

9Ibidem: "Que no de rración de vino (como se a ussado) a ningún oficial sino que lo guarde para entregar en los reales almacenes caval porque se hará carga.»

${ }^{10}$ Ibidem: "Que los días de bonanza se diga missa en el nabio y se rrece la salve y rosario de nuestra señora y acuda el dicho general a ello.»

${ }^{11}$ AGI, Filipinas 18A, R.6, N.38.

${ }^{12}$ Instrucciones otorgadas al capitán general de la San Damián, AGI, Filipinas 23, R.2, N.4: "Que si (lo que dios no permita) encontrare enemigos, trate de su defensa sin perder viage, y si no fuere posible, pelear hasta morir, usando quanto ardides hubiare.»
} 
San Damián no acabara en Japón. País con el que se mantuvieron tensas relaciones en el pasado, y que desde los decretos de Tokugawa leyasu, sus fronteras se encontraban cerradas a los hispánicos (Martínez-Shaw, 1996). Corriéndose el riego de que el galeón fuese asaltado y sus mercancías saqueadas al pasar cerca de sus costas.

Otro punto importante de las disposiciones sobre el gobierno de esta embarcación, es la relativa a la ruta que debía seguir una vez saliera de Acapulco, ya que esta fue deliberadamente alterada de su derrotero habitual. Las autoridades novohispanas, sabedoras de las escasas posibilidades de que la San Damián consiguiera cruzar el Pacífico en perfectas condiciones, decidieron cambiar el punto de arribada de la nao del puerto de Cavite a Lampón, ya que este lugar presentaba unas mejores condiciones de seguridad para una nao de las características físicas de la San Damián. ${ }^{13}$

Situado en la parte este de la isla de Luzón, Lampón era la mejor opción posible si se quería tomar puerto lo antes posible, y así asegurar la carga. Además, esta elección permitía evitar el peligroso paso por el embocadero de San Bernardino -ruta habitual de los galeones, que posibilitaba la llegada hasta Manila por el sur de Luzón-, pero por contra, tenía el inconveniente de resultar mucho menos práctica a la hora de trasladar mercancías y tropas hasta la capital de la Gobernación.

Además, la poca confianza en la seguridad de la San Damián, llevó a las autoridades mexicanas a dictaminar que se descargara el situado y los géneros transportados por galeón, en el primer puerto donde dieran fondo, no importando si este era Lampón, la lejana Cagayán o cualquiera de las Visayas. ${ }^{14}$

Estas disposiciones nos remarcan las malas condiciones de seguridad y la poca adecuación de la San Damián para realizar la carrera de Acapulco, así como las escasas esperanzas de las autoridades novohispanas en su llegada.

Como resulta evidente, muchas de estas disposiciones no llegaron a ser cumplidas ni respetadas. Así pues, por ejemplo, la primera ordenanza, en la que se fijaba como fecha inamovible para la salida del galeón el 25 de marzo, no se pudo acatar, abandonando el puerto de Acapulco once días después de lo previsto.

\footnotetext{
${ }^{13}$ Ibidem: "Que luego que se haga a la vela se ha de poner en trece grados, con la proa al rueste y con ellos ha de continuar su viage hasta llegar quarenta leguas del embarcadero de San Bernardino, de cuyo parage multiplicará altura de catorce grados y dos tercios, y por ella ha de tomar el puerto de Lampón, donde ha de surtir y dar fondo, desde cuya altura de los trece grados ha de yr con toda prebención por si encontrare enemigos."

${ }^{14}$ Ibidem: "Que si por alguna contingencia arribaren al puerto de Cagayan o a otra de las islas Philipinas, lo primero que se haga no haviendo ningún riesgo en la tierra sea hechada la plata y generos de su magestad en ella, asegurándola con la guardia y custodia que combenga y avisando luego al alcalde mayor o justicia de su magestad que hubiere en aquel partido para que le de todo el favor y ayuda que combenga a su real servicio.»
} 
Respecto a la travesía de la nao por el Pacífico y la vida de a bordo de su tripulación, se han conservado ciertas fuentes que, aunque escasas en información, nos muestran algunos aspectos sobre los meses que la San Damián pasó en alta mar. Este no es un caso excesivamente corriente, ya que las fuentes documentales relativas a la vida a bordo y a la travesía de los galeones de Manila del siglo XVII no son muy abundantes, limitándose en muchos casos a la ubicación cronológica de las fechas de llegada y partida del viaje. En el caso de la San Damián, se conservan ciertos aspectos de la travesía gracias a la presencia entre su pasaje de Diego Luis de Sanvitores, personaje de gran importancia, y destinado a cambiar el devenir del Pacífico hispano en los siguientes años. ${ }^{15}$

Sanvitores, jesuita burgalés, fue el máximo responsable de la primera campaña de evangelización de las islas Marianas -hasta entonces conocidas como Ladrones- y del consiguiente asentamiento de las armas hispánicas en estas islas, en las que murió como mártir pocos años más tarde.

Debido a ello, podemos encontrar entre sus biografías y las referencias a su vida y obra, breves menciones a su travesía con la San Damián en 1662, aunque estas se centran principalmente en el encuentro entre el jesuita y el archipiélago micronesio.

En ellas, se señalaran brevemente y sin ahondar en profundidad, ciertos aspectos de la San Damián, incidiendo en la escasa capacidad del galeón, a la que se trata de "navichuelo», y poniéndose de relieve "la estrechura del navío». En cuanto a la travesía, se remarcará que no fue muy diferente a la que llevó al jesuita de la península ibérica hasta Veracruz. Poniendo los cronistas especial atención en la actuación de Sanvitores y los otros jesuitas en "actos de contrición con los navegantes y asistencia y servicio de los enfermos como en qualquier pueblo». También se remarcará, que Sanvitores consiguió alejar durante la travesía a los navegantes del juego, actividad que pudo ser muy frecuente en los largos meses de tedio en alta mar, aludiendo que con ello "se cuidaron los juramentos, blasfemias y maldiciones que son tan ordinarias en las naos» (García, 1683: 112).

En cualquier caso, el viaje de la San Damián, cambió para siempre la vida de Sanvitores, y con ella el devenir de la Monarquía Hispánica en el Pacífico, pues durante el viaje, este galeón de Manila pasó cerca de las todavía conocidas como islas de los Ladrones.

Este archipiélago micronesio, situado en la ruta que unía Acapulco y Manila, era frecuente y únicamente visitado por los galeones que salían desde Nueva España, pues en el tornaviaje se ganaba demasiada altura para conseguir llegar a sus inmediaciones (Brunal-Perry, 2004: 547-548). A

\footnotetext{
${ }^{15}$ Algunas fuentes sitúan el embarque de Sanvitores de Acapulco hacia Filipinas en 1661, situación imposible pues ese año no salió galeón alguno con esta ruta desde la América novohispana: "Passando el año de 61 por estas islas el padre Diego Luis de San Vitores, quien a las misiones de Filippinas con los demás sujetos de la compañía de Jesús» AHN, Diversos-Colecciones, 27, N.39
} 
pesar de ser las únicas islas que se divisaban en todo el viaje transpácifico desde Acapulco, los tripulantes de los galeones no solían tomar tierra en ellas. El desconocimiento de puerto alguno en el archipiélago en el cual poder depositar un navío del calado del galeón, hizo que los hispánicos no acostumbraran a parar en las Marianas, ni se acercaran lo suficiente a ellas para tomar tierra. A pesar de estas dificultades, existía una débil y esporádica relación entre hispánicos y chamorros, ya que ante la imposibilidad de los hispánicos de tomar tierra, eran los propios marianos los que mediante sus embarcaciones se acercaban hasta los galeones para realizar pequeños intercambios. ${ }^{16}$

La visión de los marianos desnudos, acercándose a la San Damián «a rescatar hierro, cuchillos y otras cosillas semejantes, por los frutos de su tierra» supuso un fuerte impacto para el joven jesuita, quien no entendía que «estando al passo de nuestras naves nunca avían gozado de la luz del evangelio» (Garcia, 1683: 112-113). Por ello, tras su llegada a Filipinas, Sanvitores emprendió una campaña para que se le permitiera llevar a cabo la evangelización del archipiélago de las Ladrones, convenciendo tras muchas misivas, a la reina regente Mariana de Austria -de quien tomaron el nombre las islas- de la necesidad e importancia de la empresa.

Días después de su paso por las Marianas, y ante la sorpresa de los habitantes de Filipinas, la San Damián llegó al puerto de Lampón con su carga intacta. El gobernador de las islas, Sabiano Manrique de Lara, recibió la embarcación entre los más efusivos halagos al virrey conde de Baños, pues se preparaba una campaña defensiva contra el poder marítimo de la familia Zheng, en la que todos los soldados y plata eran bienvenidos y necesarios. ${ }^{17}$

Lamentablemente, la San Damián quedó severamente dañada por los rigores de tan duro viaje, haciendo imposible que pudiera volver a emprender viaje de vuelta a América. La nave fue desarmada, sus tablas arrancadas y sus piezas metálicas fundidas, siendo reutilizadas para la construcción de nuevos galeones debido a la escasez de hierro en las islas.

\footnotetext{
${ }^{16}$ Autos sobre conflicto en la ruta del galeón San José: «...eran yslas de los ladrones...y que de ellas vinieron muchas embarcaziones de yndios a esta nao a rescatar hierro como lo tienen de costumbre». AGI, Filipinas 23, R.3, N.43.

${ }^{17}$ Carta de Manrique de Lara al rey, AGI Filipinas 23, R.2, N.4: Mucho quiere Dios esta cristiandad, muestra milagrósamente su voluntad divina vía de la hazienda real de V.M como propia, y conose el rendimiento y amor con que V.M le sirve, pues teniendo escripta esta a los 13, me llegó gentil hombre de la nave que el marqués conde de Baños, virrey de la Nueva España, me remitió de socorro con 150.000 pesos y la infantería que pudo trasportar el buque surto en Lampón, remedio conocido ventajosa diligenzia del marqués. Mostrándose a todas luzes argos en prevenirles celosso en despacharle, atento a los aciertos, las notizias de su govierno son grandes, el reparo de la restauración le deve a Vuestra Magestad mereze con toda demostrazión las gracias, sirvase Vuestra Magestad de mandar se le den para que crezcan sus alientos, que ministros semejantes no se hallan a la mano de los muchos. La corona de vuestra magestad tubiera grande extenzión y la iglesia propagazión copiossa de si les professaren la ley evangélica que Vuestra Magestad catholico sustenta, los premios que vuestra magestad catholica da, ençalça más a vuestra magestad dándole a conocer en todo el mundo. El marqués será el salvador de las islas, a su actividad se las deve su magestad y a Dios la guarda que milagrosamente vemos y experimentamos
} 
Así pues, la pequeña nave Guatemalteca, de la que nadie esperaba que pudiera cruzar el Pacífico, alcanzó su objetivo, y a pesar de que lo hiciera únicamente en forma de piezas y remaches de otros galeones, su espíritu, siguió cruzando el océano Pacífico durante años.

\section{Discusión y conclusión}

El estudio pormenorizado de la nao San Damián, nos ha permitido visualizar más completa y profundamente el ámbito de actuación de los galeones de Manila, así como sus características, organización y vida a bordo. Puede que este estudio microhistórico comprenda un ámbito muy limitado de investigación, pero los resultados del mismo pueden llegar a ser de gran ayuda a la hora de tratar el comercio entre Filipinas y Nueva España desde una óptica mucho más general. Así pues, creemos que los resultados obtenidos mediante este estudio van más allá de una simple anécdota o de un caso curioso, y que el particular caso de la San Damián, puede ser una buena herramienta para mejorar el conocimiento de la Nueva España de mediados del siglo XVII, su comercio y problemática respecto a los galeones.

Por ello, y ante la muestra de los resultados obtenidos en el transcurso de nuestra investigación, podemos expresar, que aunque la San Damián supuso un proceso excepcional, con sus peculiaridades y casos especiales, muestra detalles de indudable valor para un estudio de mayor extensión. Debido a ello, esperamos que este estudio sea de especial interés para la realización de futuras investigaciones en este y otros ámbitos históricos.

\section{Bibliografía}

ARENAS Frutos, I. (2010): «¿Sólo una reina consorte de la Nueva España? 1660-1664. La II marquesa de Leiva y II marquesa de Baños.", Anuario de estudios americanos, 67, 2.

BeRnAbéU AlbeRT, S. (2000): La aventura de lo imposible: expediciones marítimas españolas. Colección ciencia y mar, Lunwerg editores, MadridBarcelona.

BRUNAL-PERRY, O. (2004): "Las islas Marianas: enclave estratégico en el comercio entre México y Filipinas» en CABRERo L. (ed.): España y el Pacífico: Legazpi, AM3, Madrid.

Coello de LA RosA, A. (2011): «Colonialismo y santidad en las islas Marianas: la sangre de los mártires (1668-1676)» en Hispania Sacra, Vol.63, nำ128, pp.707-745. 
GARCíA, F. (1683): Vida y martyrio de el venerable padre Diego Luis de Sanvitores de la compañía de ieusús, primer apóstol de las islas Marianas, y sucessos de estas islas, desde el año de mil seiscientos y sesenta y ocho, asta el de mil seiscientos ochenta y uno, Madrid.

Martínez-SHAW, C. (1996): Historia de Asia en la Edad Moderna, Arco libros, Madrid.

Prieto LuCEnA, A.M (1984): Filipinas durante el gobierno de Manrique de Lara. 1653-1663, Escuela de Estudios Hispano-Americanos de Sevilla, Sevilla.

RANGoN, P. (2010): "Servir a la corona: los pasos en falso del conde de Baños, virrey de Nueva España (1660-1664)», Anuario de estudios americanos, 67, 2.

Sales Colín, O. (2000): El movimiento portuario en Acapulco. El protagonismo de Nueva España en la relación con Filipinas, 1567-1648, Plaza y Valdés, México D.F.

SCHURz, W.L (1992): El galeón de Manila, Ediciones de cultura hispánica, Madrid.

YUSTE, C. (2007): «El galeón de Manila o nao de China» en Alfonso, M., MARTínez-ShaW, C.(edt.): La ruta española a China, El Viso, Madrid, pp.131154. 